\title{
Predictors of obstructive sleep apnoea in patients admitted for acute coronary syndrome
}

\author{
Jordi de Batlle ${ }^{1,11}$, Cecilia Turino ${ }^{1,11}$, Alicia Sánchez-de-la-Torre ${ }^{1,2}$, \\ Jorge Abad ${ }^{3}$, Joaquín Duran-Cantolla ${ }^{2,4}$, R. Douglas McEvoy ${ }^{5}$, Nick A. Antic ${ }^{5}$, \\ Olga Mediano ${ }^{6}$, Valentín Cabriada $\mathbb{1}^{7}$, Maria José Masdeu ${ }^{8}$, Joaquín Teran ${ }^{9}$, \\ Joan Valls ${ }^{10}$, Ferran Barbé $e^{1,2}$ and Manuel Sánchez-de-la-Torre ${ }^{1,2}$ on behalf of \\ the Spanish Sleep Group ${ }^{12}$
}

Affiliations: ${ }^{1}$ Respiratory Dept, Hospital Universitari Arnau de Vilanova and Santa Maria, IRBLleida, Lleida, Spain. ${ }^{2}$ Centro de Investigación Biomédica en Red de Enfermedades Respiratorias (CIBERES), Madrid, Spain. ${ }^{3}$ Respiratory Dept, Hospital Universitari Germans Trias i Pujol, Badalona, Spain. ${ }^{4}$ Medicine Dept, OSI Araba University Hospital, UPV, BioAraba Institute, Vitoria, Spain. ${ }^{5}$ Adelaide Institute for Sleep Health: A Flinders Centre of Research Excellence, Flinders University, Adelaide, Australia. ${ }^{6}$ Respiratory Dept, Hospital Universitario de Guadalajara, Guadalajara, Spain. ${ }^{7}$ Respiratory Dept, Hospital de Cruces, Bilbao, Spain. ${ }^{8}$ Respiratory Dept, Hospital Parc Taulí, Sabadell, Spain. ' Respiratory Dept, Hospital General Yagüe, Burgos, Spain. ${ }^{10}$ Unit of Bioestatistics and Epidemiology, IRBLleida, Lleida, Spain. ${ }^{11}$ Both authors contributed equally to this study. ${ }^{12} \mathrm{~A}$ list of members of the Spanish Sleep Group can be found in the Acknowledgements section.

Correspondence: Manuel Sánchez-de-la-Torre, Group of Translational Research in Respiratory Medicine, Hospital Univ Arnau de Vilanova, Rovira Roure, 80, 25198 Lleida, Spain. E-mail: sanchezdelatorrelagmail.com

@ERSpublications

Given the high prevalence of OSA in patients suffering ACS, respiratory polygraphy should be routinely performed http://ow.ly/tmKE306wyDc

Cite this article as: de Batlle J, Turino C, Sánchez-de-la-Torre A, et al. Predictors of obstructive sleep apnoea in patients admitted for acute coronary syndrome. Eur Respir J 2017; 49: 1600550 [https://doi.org/ $10.1183 / 13993003.00550-2016]$.

ABSTRACT Identifying undiagnosed obstructive sleep apnoea (OSA) patients in cardiovascular clinics could improve their management. Aiming to build an OSA predictive model, a broad analysis of clinical variables was performed in a cohort of acute coronary syndrome (ACS) patients.

Sociodemographic, anthropometric, life-style and pharmacological variables were recorded. Clinical measures included blood pressure, electrocardiography, echocardiography, blood count, troponin levels and a metabolic panel. OSA was diagnosed using respiratory polygraphy. Logistic regression models and classification and regression trees were used to create predictive models.

A total of 978 patients were included (298 subjects with apnoea-hypopnoea index (AHI) $<15$ events.h $^{-1}$ and 680 with AHI $\geqslant 15$ events. $\left.h^{-1}\right)$. Age, BMI, Epworth sleepiness scale, peak troponin levels and use of calcium antagonists were the main determinants of AHI $\geqslant 15$ events $h^{-1}$ (C statistic 0.71 ; sensitivity 94\%; specificity 24\%). Age, BMI, blood triglycerides, peak troponin levels and Killip class $\geqslant$ II were determinants of $\mathrm{AHI} \geqslant 30$ events. $\mathrm{h}^{-1}$ (C statistic of 0.67 ; sensitivity $31 \%$; specificity $86 \%$ ).

Although a set of variables associated with OSA was identified, no model could successfully predict OSA in patients admitted for ACS. Given the high prevalence of OSA, the authors propose respiratory polygraphy as a to-be-explored strategy to identify OSA in ACS patients. 


\section{Introduction}

Cardiovascular diseases represent the main cause of death worldwide, with 17.5 million victims in 2012 [1]. Coronary artery disease $(\mathrm{CAD})$ is responsible for more than half of all cardiovascular deaths, and acute coronary syndrome (ACS), ranging from unstable angina to myocardial infarction, is often the first manifestation of underlying CAD $[1,2]$. Obstructive sleep apnoea (OSA), defined as the presence of repetitive episodes of upper airway collapse during sleep, is a common chronic condition, affecting $10 \%$ of middle-aged men and $3 \%$ of middle-aged women [3]. Increased sympathetic activity and oxidative stress induced by recurrent airway obstruction, intermittent hypoxaemia and arousals from sleep, cause endothelial dysfunction and predispose patients to atherosclerosis [4]. OSA is widely recognised as a risk factor for cardiovascular diseases $[5,6]$ and increasing evidence suggests a key role and a prognostic value of OSA in ACS.

The prevalence of OSA is very high amongst patients with CAD, affecting from 57 to $79 \%$ of patients hospitalised for ACS [7-9]. Furthermore, several authors have observed worse cardiovascular outcomes when OSA coexists with ACS [10]. In patients with myocardial infarction undergoing a percutaneous coronary intervention, for example, OSA seems to promote atheroma progression, increasing the recurrence of cardiac and cerebrovascular events such as re-infarction, stroke, sudden death and repeated revascularisations [10-13]. Among such complex patients, the early identification and treatment of those with OSA may help to reduce these complications. Unfortunately, OSA remains greatly underdiagnosed in cardiology settings $[14,15]$.

Few studies to date have tried to predict the risk of suffering from OSA among patients with acute coronary syndrome using clinical variables. Furthermore, all of them have focused on a limited number of clinical variables $[16,17]$. Using data from the Impact of sleep apnoea syndrome in the evolution of acute coronary syndrome cohort (ISAACC), we performed a broad analysis of multiple clinical variables in a large cohort of ACS patients, with the aim of identifying the main determinants of OSA in such a group of patients.

\section{Methods}

\section{Study population}

This is an ancillary study of the ISAACC study, which is a multicentre, open-label, parallel, prospective, randomised, controlled trial (registered trial NCT01335087), evaluating the effect of continuous positive airway pressure (CPAP) treatment on the incidence of new cardiovascular events in patients with an episode of ACS and OSA [18]. Starting in June 2011, patients admitted for ACS to coronary care units or cardiology hospitalisation wards at 14 teaching hospitals in Spain (male and females aged $\geqslant 18$ years) were evaluated regards their suitability for the trial [18]. All patients underwent respiratory polygraphy during the first $48-72 \mathrm{~h}$ after admission. Patients with an apnoea-hypopnoea index (AHI) $>15$ events $\cdot \mathrm{h}^{-1}$ and $\leqslant 50 \%$ of central apnoeas were randomised to conservative or CPAP treatment. Those patients with an AHI $\leqslant 15$ events. $h^{-1}$ were considered controls. For the current study, we used information about the first 1000 patients recruited consecutively in the ISAACC study, excluding patients with more than 50\% of missing variables. We assessed individual predictors for OSA and developed predictive models to determine the pre-test probability of OSA based on a broad range of baseline variables in non-sleepy ACS patients, thus using the results of the respiratory polygraphy as the outcome variable.

Acute coronary syndrome was defined as the acute presentation of coronary disease with or without ST elevation infarction, unstable angina, or type 1 MI [19]. The exclusion criteria for the current study included the following: previous treatment with CPAP; psychophysical inability to complete questionnaires; the presence of any previously diagnosed sleep disorder; patients with $>50 \%$ central apnoeas or the presence of Cheyne-Stokes respiration, daytime sleepiness (Epworth Sleepiness Scale (ESS) $>10$ ), patients with chronic diseases (e.g. neoplasms, renal insufficiency (glomerular filtration rate $<15 \mathrm{~mL} \cdot \mathrm{min}^{-1} \cdot 1.73 \mathrm{~m}^{-2}$ ), severe chronic obstructive pulmonary disorder (a forced expiratory volume in $1 \mathrm{~s}<50 \%$ ), chronic depression and other limiting chronic diseases), a medical history that could interfere with the study objectives, any processes, whether cardiovascular or otherwise, that reduce life expectancy to $<1$ year, and patients in cardiogenic shock.

The ethics committee of each participating centre approved the study (approval number in the coordinator centre: 2010-852), and all patients provided written informed consent.

Support statement: The study was funded by Aller (Spain), the Catalan Cardiology Society, Esteve-Teijin (Spain), Ministerio de Economía y Competitividad (COFUND2014-51501), the Seventh Framework Programme for Research, technological development and demonstration, Sociedad Española de Neumología y Cirugía Torácica, and Fondo de Investigación Sanitaria, Ministerio de Economía y Competitividad, Una manera de hacer Europa (PI10/02763 and PI10/ 02745). Funding information for this article has been deposited with the Open Funder Registry.

Conflict of interest: Disclosures can be found alongside this article at erj.ersjournals.com 


\section{Data collection}

\section{Outcomes}

OSA diagnosis was based on the results of overnight cardio-respiratory polygraphy, which is in accordance with the guidelines of the Spanish national consensus on apnoea-hypopnoea syndrome [20]. All participating centres used the same model of polygraph (Embletta; ResMed, Bella Vista, Australia). Nasal pressure airflow, thoracoabdominal movements, electrocardiography and pulsioxymetry were recorded. Obstructive apnoea was defined as an absence of airflow lasting $\geqslant 10 \mathrm{~s}$ in presence of abdominal and thoracic movements. Central apnoeas were defined in absence of both thoracic and abdominal wall movement and airflow lasting $\geqslant 10 \mathrm{~s}$. Obstructive hypopnoea was defined as a reduction in airflow lasting $\geqslant 10 \mathrm{~s}$ associated with oxygen desaturation in presence of both thoracic and abdominal movements. Oxygen desaturation was defined as a decrease in arterial oxygen saturation $\geqslant 4 \%$. Respiratory polygraphy studies were performed without supplemental oxygen. The AHI was defined as the number of episodes of apnoea and hypopnoea per hour of recording. OSA was defined as an AHI $>15$ events $\cdot h^{-1}$ with $\leqslant 50 \%$ of central apnoeas; and severe OSA as an AHI $>30$ events $\cdot h^{-1}$ with $\leqslant 50 \%$ of central apnoeas. A minimum of $3 \mathrm{~h}$ of satisfactory signal recording were required to consider the test as valid.

\section{Covariates}

Sociodemographic variables as well as information regarding lifestyle habits, clinical background and usual pharmacological treatment were recorded using questionnaires. The degree of self-reported sleepiness/ drowsiness was analysed by the Spanish version of the Epworth Sleepiness Scale (ESS) test [21]. Quality of life was assessed with the EuroQol EQ-5D questionnaire. Anthropometric measures included weight, height, body mass index (BMI), neck, waist and hip circumferences, and the waist-to-hip ratio. Blood pressure measures, electrocardiography and echocardiography were routinely performed during patient admission. Similarly, variables related to ACS severity (ejection fraction, Killip classification, number of affected vessels, number of stents implanted and peak troponin) and short-term prognosis (length of stay in the coronary unit, length of hospitalisation, complications and mortality) were measured during patient admission. Killip classification is a clinical scale that uses physical examination to define the severity of ventricular dysfunction after a cardiac ischaemic event, predicting the risk of death, and ranging from class I (absence of heart failure signs) to class 4 (cardiogenic shock) [22]. Fasting blood samples were obtained and analysed including a complete blood count and a basic metabolic panel.

\section{Statistical analyses}

Data for each participant were uploaded to a database. Only the coordinating centre (Hospital Arnau de Vilanova and Santa Maria, IRBLleida, Lleida, Spain) had full access to the database. Given the heterogeneity of troponin measurement methods among centres, method-specific deciles of peak troponin were computed and an overall troponin variable grading from 1 to 10 was created for each subject. The mean \pm SD, median (interquartile range) or frequency (\%) were computed to evaluate the differences between OSA and control patients, assessing the significance of such differences with the Chi-squared test, t-test or Mann-Whitney test, as appropriate.

Multiple imputation techniques were used to estimate values for those patients with missing variables. Multiple imputation was implemented under the assumption that the missing data were missing at random. For each missing value, ten imputed values were generated on the basis of AHI, sex, age and reported hypertension, dyslipidaemia and diabetes. This was generated using multiple imputation by chained equations, specifying the univariate imputation model appropriate for each variable, using "mi impute chained" command in Stata (StataCorp, College Station, TX, USA), version 12.1. Crude logistic regression models were used to identify potential determinants of OSA. $\mathrm{R}^{2}$ using Fisher's $\mathrm{z}$ over imputed data and $\mathrm{C}$ statistic over imputed data were used to identify variables with predictive value for OSA. Top 20 variables according to $\mathrm{R}^{2}$ were considered for multivariate logistic regression models. After a first multivariate model including all selected variables, variables with $\mathrm{p}>0.100$ were removed from the model. In a subsequent final model, only significant variables were kept. Potential interactions among such variables were tested. Predictive value of the final model was assessed in terms of $\mathrm{R}^{2}$ using Fisher's $\mathrm{z}$ over imputed data and $\mathrm{C}$ statistic over imputed data. The same methodology was applied to assess predictors for severe OSA (AHI $>30$ events $\mathrm{h}^{-1}$ ). Additionally, sensitivity analyses excluding subjects with more than $20 \%$ of missing variables were performed.

Classification and regression trees (CART) [23] were also used as alternatives to the previously mentioned logistic regression approach to assess OSA and severe OSA. Briefly, CART provide top-down set of hierarchical variables with specified cutoff points which classify all subjects according to their probability of having OSA. Therefore, an inverted tree structure is generated, with each node corresponding to a variable and a given cutoff point, and with each dead-end branch providing the probability of such subjects having OSA. Sensitivity, specificity and predictive value of CART were assessed. CART methods were used before any multiple imputations. CART analyses were performed using the R statistical package.

Data analysis was conducted using Stata 12.1 (StataCorp, College Station, TX, USA). The threshold for significance was set at 0.05 . 


\section{Results}

A total of 978 patients were included in the analysis, after the exclusion of 22 patients with more than $50 \%$ of missing data. Up to 298 patients had AHI $<15$ events.h ${ }^{-1}$ and 680 had AHI $\geqslant 15$ events.h ${ }^{-1}$ (379 with AHI $\geqslant 30$ events. $h^{-1}$ ). The main cardio-respiratory polygraphy variables of the cohort's subjects are shown in table 1 .

Tables 2, 3 and online supplementary table S1 show all the characteristics of the ISAACC patients that were considered as potential determinants of OSA, according to AHI. The tables include information about anthropometric variables, biological determinants, usual pharmacological treatment, clinical background and lifestyle habits, cardiovascular variables and hospitalisation-related variables. OSA patients were significantly older than controls $(p<0.001)$. Similarly, OSA patients were significantly more obese than controls according to weight $(\mathrm{p}<0.001)$, body mass index $(\mathrm{p}<0.001)$, neck circumference $(\mathrm{p}<0.001)$ and waist and hip circumferences $(\mathrm{p}<0.001)$. Other very significant differences were found for peak troponin $(p<0.001)$, blood glucose $(p=0.005)$, use of calcium antagonist $(p=0.001)$, hypertension $(\mathrm{p}=0.001)$ and the Epworth Sleepiness Scale $(\mathrm{p}=0.001)$, for which OSA patients showed increased values.

After computing $\mathrm{R}^{2}$ using Fisher's $\mathrm{z}$ over imputed data and $\mathrm{C}$ statistic over imputed data to identify variables with the highest predictive value for OSA, the top 10 variables were BMI $\left(R^{2}=0.054\right)$, weight $\left(R^{2}=0.037\right)$, waist $\left(R^{2}=0.035\right)$, hip $\left(R^{2}=0.030\right)$ and neck $\left(R^{2}=0.016\right)$ circumferences, age $\left(R^{2}=0.011\right)$, peak troponin $\left(\mathrm{R}^{2}=0.010\right)$, calcium antagonists $\left(\mathrm{R}^{2}=0.010\right)$, Epworth sleepiness scale $\left(\mathrm{R}^{2}=0.009\right)$ and hypertension $\left(\mathrm{R}^{2}=0.009\right)$. The final logistic regression models attempting to predict subjects with an $\mathrm{AHI} \geqslant 15$ events $\cdot \mathrm{h}^{-1}$, as well as their prediction capacity according to $\mathrm{R}^{2}$ and the $\mathrm{C}$ statistic are shown in table 4 . The adjusted model had a C statistic of 0.71 , with a sensitivity of $94.1 \%$ and a specificity of $24.3 \%$. Similarly, table 5 shows the final logistic regression models attempting to predict severe OSA. The adjusted model had a C statistic of 0.67 , with a sensitivity of $30.5 \%$ and a specificity of $85.5 \%$. Age, BMI and the ESS were common variables to both OSA and severe OSA models. Given the poor predictive capacity of the developed models, no validation studies were performed. Sensitivity analyses excluding subjects with more than $20 \%$ of missing values reported very similar results and did not increase the predictive capacity of the models.

The use of CART did not provide better prediction capacity. Briefly, the first nodes of the classification tree for AHI $\geqslant 15$ events $\cdot \mathrm{h}^{-1}$ involved BMI, age and ESS, while for AHI $\geqslant 30$ events $\cdot \mathrm{h}^{-1}$ included BMI, prothrombin time and peak troponin levels. The former model had a sensitivity of $95 \%$ and a specificity of $43 \%$ while the later had a sensitivity of $53 \%$ and a specificity of $87 \%$. Overall, none of the resulting classification trees had a good enough performance to justify a validation study.

\section{Discussion}

In this ancillary study including 978 non-sleepy subjects from the ISAACC trial with an episode of ACS, we measured a broad range of clinical variables and assessed their association to OSA. At the same time, we tried to develop a predictive model, which could be used to identify ACS patients who should be referred for a sleep study. Age, BMI, the ESS, peak troponin levels and usual intake of calcium antagonists were the main determinants of having AHI $\geqslant 15$ events $\cdot h^{-1}$. Similarly, we identified age, BMI, blood triglycerides, peak troponin levels and having a Killip class II or higher as the main determinants of AHI $\geqslant 30$ events.h ${ }^{-1}$.

In accordance to previous literature, we found age, BMI and the ESS to be strongly associated with OSA $[16,17,24]$. However, no associations for sex were found although being previously reported [25]. Intake of one of the most widely used antihypertensive drugs, calcium antagonists, was also related to OSA, thus indicating an association between OSA and hypertension in our cohort. Additionally, we found higher

TABLE 1 Cardio-respiratory polygraphy results of the ISAACC patients according to apnoeahypopnoea index (AHI)

\begin{tabular}{|c|c|c|c|}
\hline & \multicolumn{2}{|c|}{ AHI } & \multirow[t]{2}{*}{ p-value $\#$} \\
\hline & $<15$ events $\cdot \mathrm{h}^{-1}$ & $\geqslant 15$ events $\cdot h^{-1}$ & \\
\hline Patients n & 298 & 680 & \\
\hline $\mathrm{AHI}$ events $\cdot \mathrm{h}^{-1}$ & $6(3-10)$ & $32(22-46)$ & $<0.001$ \\
\hline Oxygen desaturation index $>4 \% \mathrm{~h}^{-1}$ & $5(2-10)$ & $26(16-42)$ & $<0.001$ \\
\hline Mean $\mathrm{SaO}_{2} \%$ & $92.7 \pm 4$ & $92.0 \pm 4$ & 0.018 \\
\hline Minimum $\mathrm{SaO}_{2} \%$ & $84.4 \pm 11$ & $81.0 \pm 10$ & $<0.001$ \\
\hline Time with $\mathrm{SaO}_{2}<90 \% \%$ & $0.6(0-6.1)$ & $4.3(0.9-19)$ & $<0.001$ \\
\hline
\end{tabular}

Data are presented as mean $\pm \mathrm{SD}$ or median (interquartile range), unless otherwise stated. $\mathrm{SaO}_{2}$ : arterial oxygen saturation; AHI: apnoea-hypopnoea index. ${ }^{\#}$ : t-test or Kruskal-Wallis test as appropriate. 
TABLE 2 Baseline characteristics of the ISAACC patients according to apnoea-hypopnoea index (AHI)

\begin{tabular}{|c|c|c|c|}
\hline & \multicolumn{2}{|c|}{$\mathrm{AHI}$} & \multirow[t]{2}{*}{ p-value } \\
\hline & $<15$ events $\cdot \mathrm{h}^{-1}$ & $\geqslant 15$ events $\cdot \mathrm{h}^{-1}$ & \\
\hline Patients n & 298 & 680 & \\
\hline \multicolumn{4}{|l|}{ General characteristics } \\
\hline Age years & $58 \pm 12$ & $60 \pm 11$ & $<0.001$ \\
\hline Males n (\%) & $246(83)$ & $564(83 \%)$ & 0.881 \\
\hline Body mass index $\mathrm{kg} \cdot \mathrm{m}^{-2}$ & $27.0 \pm 4$ & $29.5 \pm 5$ & $<0.001$ \\
\hline Epworth Sleepiness Scale & $4.9 \pm 2.5$ & $5.4 \pm 2.5$ & 0.001 \\
\hline \multicolumn{4}{|l|}{ Biological determinations } \\
\hline Hematocrit \% & $42.5 \pm 5$ & $41.8 \pm 5$ & 0.046 \\
\hline Glucose $\mathrm{mg} \cdot \mathrm{dL}^{-1}$ & $102(87-134)$ & 109 (93-142) & 0.005 \\
\hline Triglycerids $\mathrm{mg} \cdot \mathrm{dL}^{-1}$ & $137.5 \pm 83$ & $146.8 \pm 77$ & 0.132 \\
\hline Total cholesterol $\mathrm{mg} \cdot \mathrm{dL}^{-1}$ & $181 \pm 46$ & $177 \pm 43$ & 0.286 \\
\hline Uric acid $\mathrm{mg} \cdot \mathrm{dL}^{-1}$ & $5.5(4.5-7.2)$ & $6.1(5-7.2)$ & 0.007 \\
\hline Creatinine $\mathrm{mg} \cdot \mathrm{dL}^{-1}$ & $0.89 \pm 0.2$ & $0.92 \pm 0.3$ & 0.093 \\
\hline Peak troponin (deciles) $)^{\pi}$ & $4(1-7)$ & $5(3-8)$ & $<0.001$ \\
\hline Creatine phosphokinase $\mathrm{UI} \cdot \mathrm{mL}^{-1}$ & $236(103-828)$ & $254(118-844)$ & 0.328 \\
\hline \multicolumn{4}{|l|}{ Usual pharmacological treatment } \\
\hline Diuretics & $45(15)$ & $128(19)$ & 0.183 \\
\hline$\beta$-blockers & $73(25)$ & 149 (22) & 0.305 \\
\hline ACE inhibitors & $38(22)$ & $90(22)$ & 0.943 \\
\hline Angiotensin II receptor antagonists & $20(12)$ & $63(16)$ & 0.228 \\
\hline Calcium antagonists & $19(7)$ & $92(14)$ & 0.001 \\
\hline Hypolipidaemics & $91(31)$ & 262 (39) & 0.022 \\
\hline Oral antidiabetics & $46(16)$ & $132(20)$ & 0.158 \\
\hline Insulin & $21(7)$ & $47(7 \%)$ & 0.908 \\
\hline
\end{tabular}

Data are presented as mean \pm SD, $\mathrm{n}(\%)$ or median (interquartile range), unless otherwise stated. \#: Chi-squared

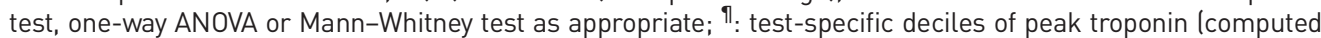
separately for each testing method to account for differences in sensitivity among centres).

peak troponin levels in OSA patients compared to controls. Some studies have also observed increased levels of plasma troponin, a sign of subclinical myocardial injury, in patients with OSA [26-28]. Moreover, a relation between troponin levels and OSA severity has been prudently suggested regardless of concerns involving a potential clustering of cardiovascular risk factors in subjects with OSA [26-28]. Finally, it is noteworthy that although not making it into the final predictive models, blood glucose levels but not diabetes was related to the risk of suffering OSA, probably due to diabetes under-diagnosis [29, 30].

Regarding severe OSA patients, we identified blood triglycerides and the Killip class as the main predictors together with age, BMI and peak troponin levels. The presence of dyslipidaemia in patients suffering OSA has been shown in several studies [31,32], and the levels of blood triglycerides represent a risk factor for cardiovascular diseases and have a prognostic role among ACS patients [33, 34]. However, LAvIE et al. [35] did not find differences in triglycerides in patients with and without OSA and CAD. Several trials have shown a worse prognosis in patients with ACS and OSA [10-13,36]. Nonetheless, no differences in troponin levels were found in a study comparing a small group of patients with CAD and untreated OSA to controls [37]. Similarly, VALO et al. [38] studied 21 patients with CAD and OSA without observing any differences with the control group. Finally, a broader study with 136 myocardial infarction patients with and without OSA showed lower levels of troponin among OSA patients, and even a cardio-protective role of OSA suggesting that OSA (or episodic hypoxia) might act as a "preconditioning factor" [39]. However, as acknowledged by the authors of previous studies, small study sample sizes could be the underlying factor explaining many of the contrasting results.

The current study has several strengths including a large sample size, the novelty of the setting in non-sleepy patients with an episode of ACS, and the measurement of a broad range of sociodemographic, anthropometric, lifestyle, biological, clinical, pharmacological and cardiovascular variables, while using respiratory polygraphy to determine OSA status. On the other hand, several limitations should be acknowledged. 1) The study is lacking the dimension of genetics; however, genetic tests are not usually available in standard clinical settings and would hinder the usefulness of the predictive model. 2) No information regarding snoring was collected as such information is not investigated in coronary units. 
TABLE 3 Baseline clinical characteristics and variables related to acute coronary syndrome severity of the ISAACC patients according to apnoea-hypopnoea index (AHI)

\begin{tabular}{|c|c|c|c|}
\hline & \multicolumn{2}{|c|}{ AHI } & \multirow[t]{2}{*}{ p-value $\#$} \\
\hline & $<15$ events $\cdot \mathrm{h}^{-1}$ & $\geqslant 15$ events $\cdot h^{-1}$ & \\
\hline Patients n & 298 & 680 & \\
\hline \multicolumn{4}{|l|}{ Clinical background } \\
\hline Hypertension & 125 (42) & 362 (53) & 0.001 \\
\hline Dyslipidaemia & $144(48)$ & 356 (52) & 0.246 \\
\hline Diabetes mellitus & 64 (22) & $168(25)$ & 0.274 \\
\hline Cardiomyopathy & $69(23)$ & 145 (22) & 0.569 \\
\hline Stroke & $7(2)$ & $25(4)$ & 0.274 \\
\hline \multicolumn{4}{|c|}{ Cardiovascular variables } \\
\hline First ACS episode & $238(85)$ & $520(82)$ & 0.199 \\
\hline Anomalies in ECG & $233(90)$ & 518 (91) & 0.621 \\
\hline \multicolumn{4}{|l|}{ ACS category } \\
\hline Unstable angina & 33 (13) & $67(12)$ & \\
\hline Non-STEMI & $125(50)$ & $268(48)$ & \\
\hline STEMI & 94 (37) & $224(40)$ & 0.736 \\
\hline Ejection fraction & $56.9 \pm 10$ & $54.9 \pm 11$ & 0.017 \\
\hline Killip Class & & & 0.060 \\
\hline I & 221 (95) & 497 (90) & \\
\hline II & $11(5)$ & $47(8)$ & \\
\hline III & $0(0)$ & $6(1)$ & \\
\hline IV & $0(0)$ & $3(1)$ & \\
\hline
\end{tabular}

Data are presented as $\mathrm{n}(\%)$ or mean $\pm S D$, unless otherwise stated. ACS: acute coronary syndrome; ECG: electrocardiogram; STEMI: ST-elevation myocardial infarction. ${ }^{\#}$ : Chi-squared test, one-way ANOVA or Mann-Whitney test as appropriate.

3) The exclusion of part of the controls modified the proportion of cases and controls, which ultimately affects the sensitivity and specificity of the predictive models; however, this fact does not diminish the predictive capacity of the models but rather shifts the model from a specificity-driven model toward a sensitivity-driven one. 4) No additional confirmatory polygraphy was available to ensure that fluid accumulation, as a symptom of acute cardiac dysfunction, was not distorting OSA diagnosis; however, polygraphies made in a subset of 57 participants after 1 year showed minor differences in median AHI: 32.0 events $\cdot \mathrm{h}^{-1}$ at baseline and 28.7 events $\cdot \mathrm{h}^{-1}$ after 1 year, thus suggesting that acute fluid accumulation was unlikely to distort OSA diagnosis. 5) The inclusion in the imputation models of subjects with up to $49 \%$ of missing variables could also be seen as a limitation; however, it is well known that analyses including only complete cases are likely to be biased due to substantial loss of precision and power [40]. Moreover, sensitivity analyses including only subjects with up to $19 \%$ of missing variables reported very similar results, thus confirming that the current results were not driven by missing values and/or

TABLE 4 Logistic regression models of potential determinants of obstructive sleep apnoea defined as apnoea-hypopnoea index $\geqslant 15$ events $\cdot h^{-1}$

\begin{tabular}{|c|c|c|c|c|c|c|c|c|}
\hline & \multicolumn{4}{|c|}{ Crude models } & \multicolumn{4}{|c|}{ Adjusted model ${ }^{\#}$} \\
\hline & OR & $95 \% \mathrm{Cl}$ & $R^{2 \pi}$ & C statistic ${ }^{+}$ & OR & $95 \% \mathrm{Cl}$ & $R^{2 \pi}$ & C statistic \\
\hline Age years & 1.02 & $1.01-1.04$ & 0.011 & 0.57 & 1.03 & $1.01-1.04$ & & \\
\hline Body mass index $\mathrm{kg} \cdot \mathrm{m}^{-2}$ & 1.15 & $1.11-1.20$ & 0.054 & 0.67 & 1.15 & $1.11-1.20$ & & \\
\hline Epworth Sleepiness Scale & 1.10 & $1.04-1.16$ & 0.009 & 0.57 & 1.08 & $1.02-1.15$ & & \\
\hline Calcium antagonists & 2.28 & $1.37-3.81$ & 0.010 & 0.54 & 1.91 & $1.11-3.28$ & & \\
\hline Peak troponin deciles ${ }^{\S}$ & 1.08 & $1.03-1.13$ & 0.010 & 0.57 & 1.08 & $1.03-1.13$ & & \\
\hline Full model & & & & & & & 0.090 & 0.71 \\
\hline
\end{tabular}

Positive predictive value over imputed data for the adjusted model=73.94\%. Negative predictive value over imputed data for the adjusted model $=64.50 \%$. \#: all covariates are together in a single model. ": $R^{2}$ using Fisher's z over imputed data; ${ }^{+}$: C statistic over imputed data; ${ }^{\S}$ : test-specific deciles of peak troponin (computed separately for each testing method to account for differences in sensitivity among centres). 
TABLE 5 Logistic regression models of potential determinants of severe OSA defined as Apnoea-hypopnoea index $\geqslant 30$ events $\cdot h^{-1}$

\begin{tabular}{|c|c|c|c|c|c|c|c|c|}
\hline & \multicolumn{4}{|c|}{ Crude models } & \multicolumn{4}{|c|}{ Adjusted model ${ }^{\#}$} \\
\hline & OR & $95 \% \mathrm{Cl}$ & $\mathrm{R}^{2 \pi}$ & C statistic ${ }^{+}$ & OR & $95 \% \mathrm{Cl}$ & $\mathrm{R}^{2 \pi}$ & C statistic ${ }^{+}$ \\
\hline Age years & 1.02 & $1.006-1.03$ & 0.007 & 0.55 & 1.03 & $1.01-1.04$ & & \\
\hline Body mass index $\mathrm{kg} \cdot \mathrm{m}^{-2}$ & 1.11 & $1.08-1.15$ & 0.040 & 0.63 & 1.11 & $1.08-1.15$ & & \\
\hline Triglycerides $\mathrm{cg} \cdot \mathrm{dL}^{-1}$ & 1.03 & $1.007-1.04$ & 0.007 & 0.55 & 1.03 & $1.01-1.05$ & & \\
\hline Peak troponin deciles $\S$ & 1.07 & $1.02-1.11$ & 0.007 & 0.56 & 1.07 & $1.02-1.12$ & & \\
\hline Killip class >1 & 2.31 & $1.39-3.88$ & 0.010 & 0.53 & 2.06 & $1.21-3.52$ & & \\
\hline Full model & & & & & & & 0.072 & 0.67 \\
\hline
\end{tabular}

Positive predictive value over imputed data for the adjusted model $=57.15 \%$. Negative predictive value over imputed data for the adjusted model $=66.04 \%$. \# : all covariates are together in a single model; ${ }^{\text {?: }} \mathrm{R}^{2}$ using Fisher's z over imputed data; ${ }^{+}$: C statistic over imputed data; ${ }^{\S}$ : test-specific deciles of peak troponin (computed separately for each testing method to account for differences in sensitivity among centres).

imputation technique. 6) The abovementioned strength of using non-sleepy subjects (ESS $\leqslant 10)$ could also be considered a weakness, as this exclusion handicaps the feasibility of an effective predictive model; however, sleepy subjects tend to be managed in sleep units and thus are not the main target of a hypothetical predictive model. 7) Not having data on the performance of screening questionnaires, such the Berlin questionnaire or the obstructive sleep apnoea in acute coronary syndrome score for the patients with ACS, precluded a comparison between them and the developed models.

This study tried to define the clinical variables that characterise patients hospitalised for ACS at higher risk of undiagnosed OSA, especially when such patients do not show significant daytime sleepiness. As expected, OSA could be suspected in older patients with high BMI and more reported sleepiness even if it would be considered not relevant enough to classify the patient as sleepy. Moreover, regular use of calcium antagonists and higher peak troponin levels, were also associated with a higher risk of OSA. However, grouping these variables into a single predictive model was insufficient to create an effective predictor model for OSA. It could be argued that, as none of the non-sleepy ACS patients are undergoing sleep tests ( $0 \%$ sensitivity and $100 \%$ specificity scenario), a predictive model calibrated in order to maximise specificity could be of some use while having a small impact on medical costs. However, such a model would have a poor sensitivity and many OSA patients would never undergo a sleep test. Therefore, options beyond predictive modelling should be explored. In this sense, the broadening application of respiratory polygraphy devices and the reduction in costs associated with domiciliary sleep tests, as well as the potential to-be-demonstrated beneficial effects of CPAP treatment, sleep testing of patients admitted for ACS could be a sound option in the near future.

In conclusion, our study failed to construct a model capable of successfully predicting OSA in patients admitted for ACS, although a set of variables associated with OSA in such patients including age, BMI and ESS but also peak troponin levels and regular use of calcium antagonists was identified. While the clinical value of correctly identifying and managing non-sleepy OSA patients who are admitted to hospital with ACS awaits the results of large randomised controlled trials of OSA treatment such as ISAACC, the authors propose the exploration of a broad use of respiratory polygraphy, rather than clinical variables, to identify OSA in ACS populations.

\section{Acknowledgements}

The authors would like to thank the patients and clinicians involved in the study, as well as the kind support from Maricel Arbonés, Silvia Ortega, and Alicia Martin (Group of Translational Research in Respiratory Medicine, IRB Lleida).

Members of the Spanish Sleep Group: Albina Aldomá, Fernando Worner, Lydia Pascual, Olga Minguez, Marina Florés, Estefania Galera, Silvia Gómez, Asunción Seminario, Luis Fernando Casas, Mireia Dalmases, Aida Muñoz Ferrer, Laura Abad Chamorro, Miguel Cervantes, Susana Pou Serramiá, Carlos Egea Santaolalla, Berenice Muria, Sandra Inglés, Jose Luis Rodriguez Manjón, Noelia Sánchez, Jose Román-Sánchez, María Isabel Valiente-Díaz, Esther Viejo-Ayuso, Amaia Urrutia Gajate, Ruth Diez Arnesto, Leire Serrano Fernández, Sonia Castro Quintas, María Piñar Fernández, Enriqueta Ramírez Prat, Isabel Rodriguez Peñalver, Luisa Alvarez Nieto, M.L. Alonso Alvarez, E. Ordax Carbajo, J.F. Masa, Jaime Corral, Mónica de la Peña, Andrés Carrillo, Ramón Coloma, Mercè Mayos, Patricia Peñacoba Toribio, J.M. Montserrat, Onintza Garmendia, Gil Bonet, Eusebi Chiner and Gemma Rubinós.

\section{References}

1 WHO Fact sheet $\mathrm{N}^{\circ} 317$. www.who.int/mediacentre/factsheets/fs317/en/ Date last accessed: July 17, 2015. Date last updated: January 2015. 
2 Kumar A, Cannon CP. Acute coronary syndromes: diagnosis and management, part I. Mayo Clin Proc 2009; 84: 917-938.

3 Peppard PE, Young T, Barnet $\mathrm{JH}$, et al. Increased prevalence of sleep-disordered breathing in adults. Am J Epidemiol 2013; 177: 1006-1014.

4 Sánchez-de-la-Torre M, Campos-Rodriguez F, Barbé F. Obstructive sleep apnoea and cardiovascular disease Lancet Respir Med 2013; 1: 61-72.

5 Gottlieb DJ, Yenokyan G, Newman AB, et al. Prospective study of obstructive sleep apnea and incident coronary heart disease and heart failure: the sleep heart health study. Circulation 2010; 122: 352-360.

6 Marin JM, Carrizo SJ, Vicente E, et al. Long-term cardiovascular outcomes in men with obstructive sleep apnoea-hypopnoea with or without treatment with continuous positive airway pressure: an observational study. Lancet 2005; 365: 1046-1053.

7 Yumino D, Tsurumi Y, Takagi A, et al. Impact of obstructive sleep apnea on clinical and angiographic outcomes following percutaneous coronary intervention in patients with acute coronary syndrome. Am J Cardiol 2007; 99: 26-30.

8 Danzi-Soares NJ, Genta PR, Nerbass FB, et al. Obstructive sleep apnea is common among patients referred for coronary artery bypass grafting and can be diagnosed by portable monitoring. Coron Artery Dis 2012; 23: 31-38.

9 Ben Ahmed H, Boussaid H, Hamdi I, et al. Prevalence and predictors of obstructive sleep apnea in patients admitted for acute myocardial infarction. Ann Cardiol Angeiol (Paris) 2014; 63: 65-70.

10 Loo G, Tan AY, Koo CY, et al. Prognostic implication of obstructive sleep apnea diagnosed by post-discharge sleep study in patients presenting with acute coronary syndrome. Sleep Med 2014; 15: 631-636.

11 Saito T, Yoshikawa T, Sakamoto Y, et al. Sleep apnea in patients with acute myocardial infarction. Crit Care Med 1991; 19: 938-941.

$12 \mathrm{Wu} \mathrm{X}, \mathrm{Lv} \mathrm{S}, \mathrm{Yu} \mathrm{X}$, et al. Treatment of OSA reduces the risk of repeat revascularization after percutaneous coronary intervention. Chest 2015; 147: 708-718.

13 Nakashima H, Katayama T, Takagi C, et al. Obstructive sleep apnoea inhibits the recovery of left ventricular function in patients with acute myocardial infarction. Eur Heart J 2006; 27: 2317-2322.

14 Costa LE, Uchôa CH, Harmon RR, et al. Potential underdiagnosis of obstructive sleep apnoea in the cardiology outpatient setting. Heart 2015; 101: 1288-1292.

15 Konecny T, Kuniyoshi FH, Orban M, et al. Under-diagnosis of sleep apnea in patients after acute myocardial infarction. J Am Coll Cardiol 2010; 56: 742-743.

16 Lee $\mathrm{CH}$, Khoo SM, Tai BC, et al. Obstructive sleep apnea in patients admitted for acute myocardial infarction. Prevalence, predictors, and effect on microvascular perfusion. Chest 2009; 135: 1488-1495.

17 Glantz H, Thunstro E, Herlitz J, et al. Occurrence and predictors of obstructive sleep apnea in a revascularized coronary artery disease cohort. Ann Am Thorac Soc 2013; 10: 350-356.

18 Esquinas C, Sánchez-de-la Torre M, Aldomá A, et al. Rationale and methodology of the impact of continuous positive airway pressure on patients with ACS and nonsleepy OSA: the ISAACC Trial. Clin Cardiol 2013; 36: 495-501.

19 Deckers JW. Classification of myocardial infarction and unstable angina: a re-assessment. Int J Cardiol 2013; 167: 2387-2390.

20 Spanish National Consensus in Sleep Apnea-Hypopnea Syndrome (SAHS). Arch Bronconeumol 2005; 41: s3-11.

21 Chiner E, Arriero JM, Signes-Costa J, et al. Validation of the Spanish version of the Epworth Sleepiness Scale in patients with a sleep apnea syndrome. Arch Bronconeumol 1999; 35: 422-427.

22 ESC Guidelines for the management of acute coronary syndromes in patients presenting without persistent ST-segment Elevation. Eur Heart J 2016; 37: 267-315.

23 Breiman L, Friedman JH, Olshen RA, et al. Classification and regression trees. Monterey, Wadsworth \& Brooks/ Cole Advanced Books \& Software, 1984.

24 Szymanski FM, Filipiak KJ, Hrynkiewicz-Szymanska A, et al. Clinical characteristics of patients with acute coronary syndrome at high clinical suspicion for obstructive sleep apnea syndrome. Hellenic J Cardiol 2013; 54: 348-354.

25 Zhao LP, Tan A, Tai BC, et al. Effects of gender on the prevalence of obstructive sleep apnea in patients with coronary artery disease. J Clin Sleep Med 2014; 10: 1279-1284.

26 Randby A, Namtvedt SK, Einvik G, et al. Obstructive sleep apnea is associated with increased high-sensitivity cardiac troponin T levels. Chest 2012; 142: 639-646.

27 Barceló A, Esquinas C, Bauçà JM, et al. Effect of CPAP treatment on plasma high sensitivity troponin levels in patients with obstructive sleep apnea. Respir Med 2014; 108: 1060-1063.

28 Einvik G, Røsjø H, Randby A, et al. Severity of obstructive sleep apnea is associated with cardiac troponin I concentrations in a community-based sample: data from the Akershus Sleep Apnea Project. Sleep 2014; 37: 1111-1116.

29 Fraser LA, Twombly J, Zhu M, et al. Delay in diagnosis of diabetes is not the patient's fault. Diabetes Care 2010; 33: e10.

30 Levetan CS, Passaro M, Jablonski K, et al. Unrecognized diabetes among hospitalized patients. Diabetes Care 1998; 21: 246-249.

31 Nadeem R, Singh M, Nida M, et al. Effect of obstructive sleep apnea hypopnea syndrome on lipid profile: a meta-regression analysis. J Clin Sleep Med 2014; 10: 475-489.

32 Iesato K, Tatsumi K, Saibara T, et al. Decreased lipoprotein lipase in obstructive sleep apnea syndrome. Circ $J$ 2007; 71: 1293-1298.

33 Schwartz GG, Abt M, Bao W, et al. Fasting triglycerides predict recurrent ischemic events in patients with acute coronary syndrome treated with statins. J Am Coll Cardiol 2015; 65: 2267-2275.

34 Wan $\mathrm{K}$, Zhao J, Huang $\mathrm{H}$, et al. The association between triglyceride/high-density lipoprotein cholesterol ratio and all-cause mortality in acute coronary syndrome after coronary revascularization. PLoS One 2015; 10: e 0123521.

35 Lavie L, Perelman A, Lavie P. Plasma homocysteine levels in obstructive sleep apnea: association with cardiovascular morbidity. Chest 2001; 120: 900-908.

36 Glantz H, Thunström E, Johansson MC, et al. Obstructive sleep apnea is independently associated with worse diastolic function in coronary artery disease. Sleep Med 2015; 16: 160-167. 
37 Gami AS, Svatikova A, Wolk R, et al. Cardiac troponin T in obstructive sleep apnea. Chest 2004; 125: 2097-2100.

38 Valo M, Wons A, Moeller A, et al. Markers of myocardial ischemia in patients with coronary artery disease and obstructive sleep apnea: effect of continuous positive airway pressure therapy. Clin Cardiol 2015; 38: 462-468.

39 Shah N, Redline S, Yaggi HK, et al. Obstructive sleep apnea and acute myocardial infarction severity: ischemic preconditioning? Sleep Breath 2013; 17: 819-826.

40 Sterne JA, White IR, Carlin JB, et al. Multiple imputation for missing data in epidemiological and clinical research: potential and pitfalls. BMJ 2009; 338: b2393. 